\title{
Maternal and neonatal outcomes in vacuum assisted births in the government tertiary care hospital in Mandya: a retrospective record- based study
}

\author{
Shwetha M., Shilpa M. N.*
}

Department of Obstetrics and Gynecology, Institute of Medical Sciences, Mandya, Karnataka, India

Received: 01 February 2020

Accepted: 10 February 2020

\section{*Correspondence:}

Dr. Shilpa M. N.,

E-mail: shilpahattin@gmail.com

Copyright: () the author(s), publisher and licensee Medip Academy. This is an open-access article distributed under the terms of the Creative Commons Attribution Non-Commercial License, which permits unrestricted non-commercial use, distribution, and reproduction in any medium, provided the original work is properly cited.

\begin{abstract}
Background: Vacuum extraction and forceps are the two options when an instrument is needed to facilitate a vaginal birth. Vacuum extraction has recently gained popularity because of new designs of vacuum cups with reduced risk of injury to the neonate. Vacuum extraction is one of the evidence-based interventions that can prevent complications by shortening the second stage of labour. The present study has been carried out to evaluate the maternal and neonatal morbidity, mortality and failure associated with vacuum assisted vaginal deliveries, at a Government tertiary care hospital in Mandya, Karnataka, India.

Methods: The study was a record-based study including a total of 207 women who underwent vaginal assisted delivery in the form of vacuum assisted deliveries in a period of 6 months from January 2019 to June 2019 at the Government tertiary care hospital in Mandya, Karnataka, India. Records of women who had vacuum assisted deliveries and records of their newborn children were accessed.

Results: In our study $41.5 \%$ of the subjects were in the age group of $21-25$ years. Nearly $3 / 4^{\text {th }}(74.4 \%)$ of the subjects were primigravida. More than half $(54.1 \%)$ of the study subjects had to be put under vacuum assisted techniques for delivery because of the prolonged second stage of labour, failure rate was $0.4 \%$. Out of 207 vacuum assisted deliveries maternal complication rate was $8.21 \%$, $17.3 \%$ neonates had NICU admission and $14.97 \%$ had perinatal complications.

Conclusions: Vacuum assisted vaginal delivery is comparatively a better choice in preventing the complications caused due to prolonged second stage of labour thus reducing the cesareans rate. It is a safe alternative to cesareans delivery in rightly chosen case. Vacuum assisted delivery by a skilled person and a proper technique is associated with lesser maternal and neonatal morbidity.
\end{abstract}

Keywords: Forceps, Instrumental deliveries, Neonatal intensive care unit, Perinatal complications, Vacuum

\section{INTRODUCTION}

Operative vaginal delivery is the delivery conducted by using forceps or vacuum extractor. It remains a valid option when the problems arise in second stage of labour. The maternal and fetal morbidity due to prolonged labour, maternal exertion, etc compel the doctors to expedite the process of delivery by using instruments like vacuum or forceps to save the baby. ${ }^{1,2}$
The incidence varies from country to country and even in the same country from one obstetrician to other. Approximately $10 \%$ of all deliveries in the western world are accomplished by one of the two methods of operative vaginal birth, vacuum extraction or forceps. Forceps extractions are preferred in the United States, Canada, South America and Eastern Europe while vacuum is the instrument of choice in Western Europe, Asia and middle east. $^{3,4}$ In the RCOG consultant conference, the 
instrumental vaginal delivery rate of $10.5 \%$ was reported with a range of 4-20\%. ${ }^{5}$ The choice between forceps and vacuum options has usually been based on tradition and training.

Although the use of caesarean delivery has grown considerably and is considered safe by many, but surgical vaginal delivery has a great advantage of reducing the complications associated with caesarean section, such as death, postpartum hemorrhage (PPH), wound disruption and injury to bladder, venous thromboembolism, infection, recovery time, rising costs, and subsequent repeat caesarean section. ${ }^{6,7}$

The decrease in surgical vaginal delivery is due to the risk of adverse court judgments against the doctor in the case of a problem. ${ }^{6,7}$ Vacuum extraction has recently gained in popularity because of new designs of vacuum cups with reduced risk of injury to the neonate and increased instrumental success rate. ${ }^{3,8}$ It avoids caesarean section and its associated morbidity and implications for future pregnancy. ${ }^{9}$

An important cause of maternal and perinatal morbidity and mortality is prolonged second stage of labour and its complications such as haemorrhage, sepsis, uterine rupture, obstetric fistula and birth asphyxia. ${ }^{10-12}$ Vacuum extraction is one of the evidence-based interventions that can prevent complications by shortening the second stage of labour. ${ }^{13-16}$

If vacuum application fails, a caesarean section is needed. There are some risks with vacuum-assisted delivery, but it rarely causes lasting problems when properly used. ${ }^{17}$ Immediate and short-term maternal complications include perineal lacerations, cervical and vaginal lacerations, urinary tract infection, pelvic floor injuries. Fetal and neonatal complications include shoulder dystocia, subdural hemorrhage, facial nerve palsy, subconjunctival hemorrhage, retinal hemorrhage, intracranial hemorrhage, scalp laceration, and cervical injury. ${ }^{6}$

With this background the present study has been carried out to evaluate the maternal and neonatal morbidity, failure and complications associated with vacuum assisted vaginal deliveries, at the Government tertiary care hospital in Mandya, Karnataka, India.

\section{METHODS}

The study was a record-based study including a total of 207 women who underwent assisted vaginal delivery in the form of vacuum assisted deliveries in a period of 6 months from January 2019 to June 2019 in a government tertiary care hospital in Mandya, Karnataka, India.

\section{Inclusion criteria}

- All women who had vacuum assisted deliveries and records of their newborn children.
Vacuum deliveries were performed by application of silastic cups. The information related to cervical lacerations, vaginal laceration, perineal tear, episiotomy extensions or paraurethral tear and other maternal outcome were noted. New-born outcome in terms of Apgar score 1 and 5 min, NICU admissions, convulsions, instrumental injuries or complications (Cephalhematomas, Caput succedaneum, Jaundice, neonatal sepsis) were noted. The institutional ethics committee approval was taken prior to the start of the study.

\section{Statistical analysis}

Data was entered in MS excel spreadsheet. Descriptive analysis like percentage, proportion, mean, standard deviation was used.

\section{RESULTS}

Total number of deliveries in six months (Jan-June 2019) in our institute was 4090 , out of which vacuum assisted deliveries were $207(5.1 \%)$. In the study mean age of subjects was $23.61 \pm 3.95$ years. The minimum age was 18 years and the maximum being 35 years.

\section{Table 1: Distribution of subjects by their age group} in years.

\begin{tabular}{|lll|}
\hline Age in year & Frequency $(\mathbf{n}=\mathbf{2 0 7})$ & Percent \\
\hline $18-20$ & 59 & 28.5 \\
\hline $21-25$ & 86 & 41.5 \\
\hline $26-30$ & 52 & 25.1 \\
\hline $31-35$ & 10 & 4.8 \\
\hline Total & $\mathbf{2 0 7}$ & $\mathbf{1 0 0 . 0}$ \\
\hline
\end{tabular}

Table 1 depicts the distribution of the subjects by their age group in years. $41.5 \%$ women were in the age group of $21-25$ years, followed by $28.5 \%$ in $18-20$ years, $25.1 \%$ in $26-30$ years and $4.8 \%$ in $31-35$ years.

Table 2: Gravida status and period of gestation (POG) categories among the subjects.

\begin{tabular}{|lll|}
\hline Gravida & Frequency $(\mathbf{n}=\mathbf{2 0 7})$ & Percent \\
\hline Primi & 154 & 74.4 \\
\hline Multi & 53 & 25.6 \\
\hline POG & & \\
\hline $36.00-38.00$ & 28 & 13.5 \\
\hline $38.01-40.00$ & 140 & 67.6 \\
\hline$>40.00$ & 39 & 18.8 \\
\hline Total & $\mathbf{2 0 7}$ & $\mathbf{1 0 0 . 0}$ \\
\hline
\end{tabular}

Table 2 shows, nearly $3 / 4^{\text {th }}(74.4 \%)$ of the subjects were primigravida and the remaining multi-gravida. More than $2 / 3^{\text {rd }}(67.6 \%)$ of the subjects were in the gestational age of 38 to 40 weeks, the remaining were in 36 to 38 weeks $(13.5 \%)$ and more than 40 weeks $(18.8 \%)$. 
Table 3: Indications for vacuum applications among the subjects.

\begin{tabular}{|lll|}
\hline Indications & $\begin{array}{l}\text { Number } \\
(\mathbf{n}=\mathbf{2 0 7})\end{array}$ & Percent \\
\hline Poor maternal efforts & 42 & 20.2 \\
\hline Cut short $2^{\text {nd }}$ stage of labour & 15 & 7.2 \\
\hline Fetal distress & 38 & 18.3 \\
\hline Prolonged $2^{\text {nd }}$ stage of labour & 112 & 54.4 \\
\hline
\end{tabular}

Table 3 depicts, more than half $(54.4 \%)$ of the study subjects had to be put under vacuum assisted techniques for delivery because of the prolonged second stage of labour. $20.2 \%$ of them for poor maternal efforts, $18.3 \%$ for fetal distress and the remaining $7.2 \%$ to cut short $2^{\text {nd }}$ stage of labour.

Table 4: Maternal complication rate among the subjects.

\begin{tabular}{|lll|}
\hline Maternal complications & $\begin{array}{l}\text { Frequency } \\
(\mathbf{n = 2 0 7})\end{array}$ & Percent \\
\hline Postpartum hemorrhage & 3 & 1.4 \\
\hline Vaginal wall tear & 8 & 3.8 \\
\hline $\begin{array}{l}\text { Perineal tear }\left(2^{\text {nd }} \text { and } 3^{\text {rd }}\right. \\
\text { degree })\end{array}$ & 3 & 1.4 \\
\hline Retained placenta & 1 & 0.5 \\
\hline Cervical tear & 2 & 0.96 \\
\hline Total & $\mathbf{1 7}$ & $\mathbf{8 . 2 1}$ \\
\hline
\end{tabular}

The total maternal complication rate was $8.21 \%$. Eight of the subjects had vaginal wall tear, 3 each had postpartum haemorrhage and perineal tear, 2 had cervical tear and a subject had retained placenta. The same is depicted in the Table 4.

Table 5: Apgar score.

\begin{tabular}{|lll|}
\hline Apgar score & $\mathbf{0 - 3}$ & $\mathbf{4 - 6}$ \\
\hline At $1 \mathrm{~min}$ & $3(1.4 \%)$ & $17(8.1 \%)$ \\
\hline At $5 \mathrm{~min}$ & $2(0.9 \%)$ & $9(4.3 \%)$ \\
\hline
\end{tabular}

The above Table 5 shows the Apgar score in the neonates who underwent vacuum assisted delivery. Total $3(1.4 \%)$ neonates had APGAR score of $0-3$ at $1 \mathrm{~min}, 2(0.9 \%)$ at 5 $\min$.

Table 6: Neonates by NICU admission requirement.

\begin{tabular}{|lll|}
\hline NICU admission & Frequency & Percent \\
\hline Yes & 36 & 17.3 \\
\hline No & 171 & 82.6 \\
\hline
\end{tabular}

A total of 36 babies (17.3\%) required NICU admission. The average NICU stay was $3.06 \pm 2.3$ days, median being 2 days, with a minimum of 1 day and a maximum of 11 days. There was one neonatal death due to perinatal asphyxia. One case of vacuum application failed and required delivery by caesarean section.

Table 7: Perinatal complications rate.

\begin{tabular}{|lll|}
\hline Neonatal complication & $\begin{array}{l}\text { Frequency } \\
(\mathbf{n}=\mathbf{2 0 7})\end{array}$ & Percent \\
\hline $\begin{array}{l}\text { Total number of neonates } \\
\text { with perinatal asphyxia }\end{array}$ & 31 & 14.9 \\
\hline Perinatal asphyxia & 9 & 4.3 \\
\hline Neonatal depression & 8 & 3.8 \\
\hline ERBS palsy & 1 & 0.4 \\
\hline Hyperbilirubinemia & 5 & 2.4 \\
\hline Convulsions & 1 & 0.4 \\
\hline Hypernatrimia & 2 & 0.9 \\
\hline TTNP & 1 & 0.4 \\
\hline MAS & 3 & 1.4 \\
\hline $\begin{array}{l}\text { Perinatal asphyxia+ ERBS } \\
\text { palsy }\end{array}$ & 1 & 0.4 \\
\hline Total & $\mathbf{3 1}$ & $\mathbf{1 4 . 9 7}$ \\
\hline
\end{tabular}

A total $14.97 \%$ had perinatal complications which included perinatal asphyxia, neonatal depression, hyperbilirubinemia, hypernatremia, meconium aspiration syndrome, ERBs palsy, convulsions, and others. The most common being perinatal asphyxia (Table 7).

\section{DISCUSSION}

Total number of deliveries in 6 months (Jan 2019 to June 2019) was 4090 out of which 207 were delivered by vacuum assisted vaginal delivery. Incidence of vacuum deliveries in our institute is $5.1 \%$.

In our study, $41.5 \%$ of the subjects were in the age group of $21-25$ years, followed by $28.5 \%$ in $18-20$ years, $25.1 \%$ in $26-30$ years and $4.8 \%$ in $31-35$ years.

Nearly $3 / 4^{\text {th }}(74.4 \%)$ of the subjects were primigravida and the remaining multi-gravida. More than $2 / 3^{\text {rd }}(67.6 \%)$ of the subjects were in the gestational age of 38 to 40 weeks, the remaining were in 36 to 38 weeks (13.5\%) and more than 40 weeks $(18.8 \%)$. In our study more than half $(54.4 \%)$ of the study subjects had to be put under vacuum assisted techniques for delivery because of the prolonged second stage. $20.2 \%$ of them for poor maternal efforts, $18.3 \%$ for fetal distress and the remaining $7.2 \%$ to cut short $2^{\text {nd }}$ stage of labour. In a study done by Faisal $\mathrm{S}$ et al, the incidence of instrumental vaginal delivery was $2.8 \%$ of all deliveries, most of the patients were between 20-30 years $(88 \%)$ and maximum being primigravida (57.19\%) and the most common indication was prolonged second stage $(70.6 \%) .{ }^{5}$ Our findings are similar to the study done by Faisal $\mathrm{S}$ et al, and Chaudhari et al. ${ }^{5,8}$

The total maternal complication rate was $8.2 \%$. Eight of the subjects had vaginal wall tear, 3 each had postpartum hemorrhage and perineal tear, 2 had cervical tear and one subject had retained placenta. Only $14.97 \%$ had perinatal 
complications which included perinatal asphyxia, neonatal depression, hyperbilirubinemia, hypernatremia, meconium aspiration syndrome, Erbs palsy, convulsions, and others. The most common being perinatal asphyxia. These findings are in line with the study done by Chaudhari et al, Jason B et al, and Shresta et al except the neonatal morbidity rate which is less in our study, compared to few studies as even the experience, techniques of vacuum application and facilities at the intra-natal period make an impact in prevention of the complications. ${ }^{8,18-20}$

Chaudari $\mathrm{P}$ et al, in Uttarakhand found that in vacuum assisted deliveries 68\% women needed episiotomy, 9\% had perinial tear, $3 \%$ had vaginal / periurethral tear, $1 \%$ had post partumhemorrage and $1 \%$ needed blood transfusion. Morbidities of the newborns were $13 \%$ had NICU admissions, $18 \%$ neonates had cephalhematoma, $13 \%$ had hyperbilirubinemia, $11 \%$ had bruising, $5 \%$ had convulsions, $5 \%$ had feeding difficulties and $1 \%$ had irritability. $^{8}$

Shresta et al in Nepal found that, the most common $(62.5 \%)$ indication for vacuum application was prolonged second stage of labor followed by fetal distress (19.2\%), poor maternal effort $(9.6 \%)$, and to shorten the second stage $(8.6 \%)$. The overall rate of maternal morbidity with vacuum assisted vaginal delivery was $17.3 \%$ with no mortality. Neonatal morbidities were present in $25.0 \%$ neonates and the most common was birth asphyxia $(19.2 \%)$ followed by cephalohematoma (4.8\%), and brachial plexus injury $(0.96 \%)$. There was one $(0.96 \%)$ early neonatal death due to meconium aspiration syndrome. ${ }^{20}$

Jason B et al in USA found that maternal morbidity among nulliparous women who underwent vacuum assisted delivery was $31 \%$, third and fourth degree perineal tear was $16 \%$, infections were $10 \%$, lacerations were $5 \%$, hemorrhage was $5 \%$ and $<1 \%$ had to stay in the hospital for more than 5 days. ${ }^{19}$ Neonatal morbidity for vacuum assisted vaginal births in California between 2008 to 2012 was $13.3 \%$. 5.7\% had respiratory problems, $3.4 \%$ had to stay in the hospital for more than 5 days, $1.3 \%$ had Apgar $<7,2.7 \%$ had shoulder dystocia, $2.3 \%$ had infections, $0.8 \%$ had neurological injury and $0.7 \%$ had skeletal injury. ${ }^{19}$

In our study the average NICU stay was 3.06 \pm 2.3 days, median being 2 days, with a minimum of 1 day and a maximum of 11 days. There was one neonatal death due to perinatal asphyxia. One case of vacuum application failed and required delivery by caesarean section. The neonatal morbidity rate varies across regions and among different studies, but vacuum is generally considered as a safe alternative to forceps, concerning the neonatal morbidity. ${ }^{21,22}$

\section{CONCLUSION}

Vacuum assisted vaginal delivery is a safe alternative to caesarean delivery in rightly chosen case. Vacuum assisted delivery by a skilled person and a proper technique is found to be safer and associated with lesser maternal and neonatal morbidity and mortality. Though the expertise is required in both the types of instrumental application, many obstetricians are comfortable with vacuum extraction and many studies have shown it to be safer than forceps. Improved training in instrumental delivery might help in reducing the complication rate and also the raising caesarean rate.

\section{Funding: No funding sources}

Conflict of interest: None declared

Ethical approval: The study was approved by the Institutional Ethics Committee

\section{REFERENCES}

1. Cunningham FG, Leveno KJ, Bloom SL, Spong CY, Dashe J. Operative vaginal delivery. In: Cunningham FG, Leveno KJ, Bloom SL, Spong CY, Dashe J, eds. Williams Obstetrics. 24 $4^{\text {th }}$ ed. New York, NY: McGraw-Hill Education; 2014:574-586.

2. American College of Obstetricians and Gynecologists. Practice Bulletin No.154: Operative vaginal delivery. Obstet Gynecol. 2015;126:e56-65.

3. Prapas N, Kalogiannidis I, Masoura S. Operative vaginal delivery in singleton term pregnancies: shortterm maternal and neonatal outcomes. Hippokratia. 2008;13(1):41-5.

4. Nolens, Lule J, Namiiro F, van Roosmalen J, Byamugisha J. Audit of a program to increase the use of vacuum extraction in Mulago Hospital, Uganda Barbara. BMC Preg Childbirth. 2016;16:258.

5. Shameel F, Bava A, Nandanwar YS. Instrumental vaginal deliveries at tertiary centre. Int $\mathrm{J}$ Reprod Contracept Obstet Gynecol. 2016;5:4146-50.

6. Jeon J, Sunghun NA. Vacuum extraction vaginal delivery: current trend and safety. Obstet Gynecol Sci. 2017;60(6):499-505.

7. McQuivey RW. Vacuum-assisted delivery: a review: J Maternal-Fetal Neonat Med. 2004;16:171-9.

8. Chaudhari P, Bansal N, Gupta V, Tandon A, Chaudhry A. A comparative study of feto-maternal outcome in instrumental vaginal delivery at tertiary health level hospital in Uttarakhand state. Int $\mathbf{J}$ Reprod Contracept Obstet Gynecol. 2016;5:3294-9.

9. Ajit V. Assisted delivery. Pract Obstet Gynecol. APC Publications. 2016:216.

10. Kassebaum NJ, Bertozzi-Villa A, Coggeshall MS, Shackelford KA, Steiner C, Heuton KR, et al. Global, regional and national levels and causes of maternal mortality during 1990-2013: a systematic analysis for the Global Burden of Disease Study 2013. Lancet. 2014;384:980-1004. 
11. Hofmeyr GJ. Obstructed labor: using better technologies to reduce mortality. Int $\mathbf{J}$ Gynaecol Obstet. 2004;85 Suppl1:S62-72.

12. Mbaruku G, van Roosmalen J, Kimondo I, Bilango F, Bergstrom S. Perinatal audit using the 3-delays model in western Tanzania. Int $\mathbf{J}$ Gynaecol Obstet. 2009; 106:85-8.

13. Committee on Practice Bulletins-Obstetrics. ACOG Practice Bulletin No. 154: Operative Vaginal Delivery. Obstet Gynaecol. 2015;126(5):e56-65.

14. Green-top guideline no. 26: Operative vaginal delivery. Royal College of Obstetricians and Gynaecologists, 2011. Available at: http://www.rcog.org.uk/globalassets/documents/guid elines/gtg_26.pdf. Accessed on $3^{\text {rd }}$ February 2016.

15. Ministry of Health, Uganda. Uganda safe motherhood life-saving skills trainin. In: Trainees' handbook. The Republic of Uganda: Reproductive Health Division, MOH; 2012.

16. Nolens B, Lule J, Namiiro F, Roosmalen JV, Byamugisha J. Audit of a program to increase the use of vacuum extraction in Mulago Hospital, Uganda. BMC Preg Childbirth. 2016;16:258.

17. Unzila AA, Errol RN. Vacuumy. Reviews in OBG. 2009;2(1):5-17.

18. Jason B, Deirdre L, Yasser ES, Amen N, Megan F, Caterine B, et al. Maternal morbidity after forceps vs vacuum assisted delivery - outcomes from a large state-wide cohort. Am J Obstet Gynecol. 2018;218(1):S345.

19. Jason B, Deirdre L, Yasser ES, Amen N, Megan F, Caterine B, et al. Neonatal outcomes after operative vaginal delivery - are forceps or vacuum safer? Am J Obstet Gynecol. 2018;218(1):S343.

20. Shrestha BK, Shrestha B, Thapa B. Vacuum assisted vaginal delivery in singleton term pregnancies: short term maternal and neonatal outcome in a tertiary hospital of Nepal. J Lumbini Med Coll. 2016;4(2):104-7.

21. Demissie K, Rhoads GG, Smulian JC, Balasubramanian BA, Gandhi K, Joseph KS, et al. Operative vaginal delivery and neonatal and infant adverse outcomes: population based retrospective analysis. BMJ. 2004;329(7456):24.

22. Prameela RC, Prajwal S. Assisted vaginal delivery, Forceps, Ventouse. Outcome of instrumental vaginal deliveries in referred cases. J Evolut Med Dent Sci. 2015;4(19):3275-80.

Cite this article as: Shwetha M, Shilpa MN.

Maternal and neonatal outcomes in vacuum assisted births in the government tertiary care hospital in Mandya: a retrospective record-based study. Int J Reprod Contracept Obstet Gynecol 2020;9:965-9. 